\title{
Classification of The Insured On The Basis Of The Customers Loyalty Through Using Data Mining Techniques
}

\author{
Fateme Sadat Mousavi \\ Department of Computer \\ Science and Research \\ Islamic Azad University \\ Guilan, Iran
}

\author{
Maryam Khademi \\ Department of Applied \\ Mathematics \\ Islamic Azad University \\ Tehran, Iran
}

\author{
Hamid Reza Ahmadifar \\ Department of Computer \\ Guilan University \\ Guilan, Iran
}

\begin{abstract}
Insurance companies ask for too much information about their customers and the information was saved in their data base for many years, customers and prediction of their requirements as well as estimation of future customers were all classified on the basis of experimental inferences and guessing of the insurance companies. Therefore, most of the insurance companies carried out new and intelligent researches and investigations about their own customers through using information technology tools.

The main purpose of this research is to identify the loyal customers who have bought fire insurance policy and have extended it. The data available in information bank system of fire insurance in a private company has been investigated in the country during four years.

The obtained results involve classification and grouping of fire insurances on the basis of decision tree by using Rapidminer software. After that, the test data are separated from train data randomly and it is determined that $70 \%$ of data are used for training and the remaining $30 \%$ of data are expended for testing.
\end{abstract}

Keywords: Customers Classification and Grouping, Insurance Industry, Data Mining, Decision Tree, Rapidminer

\section{INTRODUCTION}

One of the important issues affecting on the management of dynamic companies such as insurance companies is related to customer relationship management. Using communicative and information technologies and tools as well as obtaining improved customer relationship management provide the continuous relationship with the customers and create their satisfaction and loyalty. In addition, it provides profits for insurance companies, and results in obtaining competitive advantages in comparison to other competitors. Hence, customer relationship management has been considered as the most important and strategic in organizations' decision making.According to obtained experiences, those organizations that consider the concepts of customer, goods, market, sales, shopping, competition, propaganda and quality as traditional concepts fail to be successful, and lose their investments as well [1]

\section{NECESSITY OF CUSTOMER CLASSIFICATION}

In recent years, the relationship between companies and customers has considerably changed. The organizations have found out that their success depends on proper understanding of the customers, prediction and considering their requirements and wants [5]. Therefore, classification of the current customers with the aim of presenting improved services and obtaining customers' loyalty has great and special importance. In addition, this classification allows the insurance companies to recognize and identify the aim of markets and potential customers according to behaviors patterns of the current customers. Also, it allows them to take into account marketing activities.

\section{APPLICATIONS OF DATA MINING IN INSURANCE INDUSTRY}

One of the problems of statistical analysis is that there are great data in insurance companies. The most important characteristics of data mining analyze data among great data or data storage. Due to this issue, analysts can analyze data easily. Nowadays, data mining has considerable role in the analysis carried out by insurance companies [3].

\subsection{Customer Relationship Management}

Nowadays, in competitive business, strong and stable management of customer relationship allows the companies to identify the profitable customers, and to create long-term plans for retention of their loyalty. The main and key competitive factors that should be taken into account by insurance companies are as follows: identifying profitable customers, retention of their loyalty for as long time and developing relationships. Through using data mining, insurance companies can determine the value of the customers and can predict their future behaviors. In this way, they can make certain decisions.

\subsubsection{Dimensions of Customer Relationship Management}

Four dimensions of CRM include:

- Customer Identification

- Customer Attraction 
- Customer Retention

- Customer Development

These four dimensions can be considered as closed loop of customer relationship management.

\subsubsection{Customers Identification}

Customer relationship management begins with identification of the customers. This stage involves recognizing population who will be probably our customers or will be profitable. The elements of customer identification contain the analysis of target customers and customers grouping and classification. The analysis of customers includes searching profitable parts of the customers on the basis of basic characteristics of the customers. Customers' grouping and classification consist of dividing all customers into smaller groups, and involve relatively similar customers in each group.

In this research, according to above mentioned dimensions of customer relationship management, classification of current

\subsubsection{Customers Attraction}

After the stage of customer identification, this stage begins. Then based on identifying the potential customers, organizations can target the attempts and resources of direct attraction of the customers. The element of customer attraction is direct marketing. Direct marketing includes development process, and stimulates the customers to order through various channels. For example, direct email and/or distribution of coupons are direct marketing [6].

\subsubsection{Customer Retention}

This stage is the main topic of CRM. The main condition of customer retention is customer satisfaction, and this indicates the customers' expectations, wants and understanding their satisfaction. The elements of customer retention include individual marketing, personal marketing that is supported by analysis, identifying and predicting the changes occurring in the customers. Loyalty programs involve supporting activities with the aim of establishing long-term relations with the customers, credit ranking, and the quality of services or satisfaction of loyalty programs [6].

\subsubsection{Customers Development}

This stage consists of developing abundant transactions, value of transactions and recalling the customers. The elements of developing customers involve the analysis of customers' life period value and cross and up, and indicate promotion activities with the aim of increasing the related services that a customer presents. The main goal of market basket is to increase abundant transactions of the customer and to reveal the procedures in customers' behaviors.

The aim of CRM dimensions is to provide deep understanding of the customers, and to maximize customers' value for a long time. Indeed, the analysis of customers relationship management, behaviors and characteristics of the customers not only allows the managers to make future decisions about the company but also presents a competitive strategy for attraction and retention of the current customers as well as getting new customers.

\subsection{Attraction of New Customers and Increasing Market Share}

One of the important issues related to attraction of new customers is the way of presenting the rate. In traditional methods, increasing customers' attraction is as same as increasing the attempts of sales unit, but if these attempts are directed by the achievements obtained through extracting data, better results will be obtained [2].

\subsection{Finding Potential Customers}

Potential customersrefer to those customers changing into a good customer if they behave the customers in a proper way. Frequently, data mining has an important role in finding the customers. The most important results of this studyobtained data mining in customer service are as follows:

- Recognizing and identifying good customers

- Selecting the suitable channel to reach to potential customers

- $\quad$ Selecting the suitable message for various groups of customers

\subsection{Determining Rate of Insurance Premium}

One of the important issues affecting on the survival and retention of the customers and attending to them is the way of presenting the goods price and rate or presenting services by the organization. Hence, the way of determining the cost has an important role in retention of market share and the profitability of insurance companies. The insurance prices should be enough attractive for the customers, and should have competitive advantage. Also, it should have the advantage of compensation of damages and company prices [4].

In insurance industry, like other industries, the customer can select its own insurer. Some factors are involved in this decision such as price, the quality of services and 
personal inclinations. In such environments, it is important to identify the customers leaving the company, and to determine the reason for taking preventive actions and retention of the customers.

\section{IMPLEMENTATION OF SUGGESTED METHOD}

Output model of decision tree classification has been demonstrated in figure 1.4 in terms of customers' loyalty. In this model, depth of the tree is equal to fourteen, and reliability method is X-Validation. Insurance record has been selected as dependent variable.

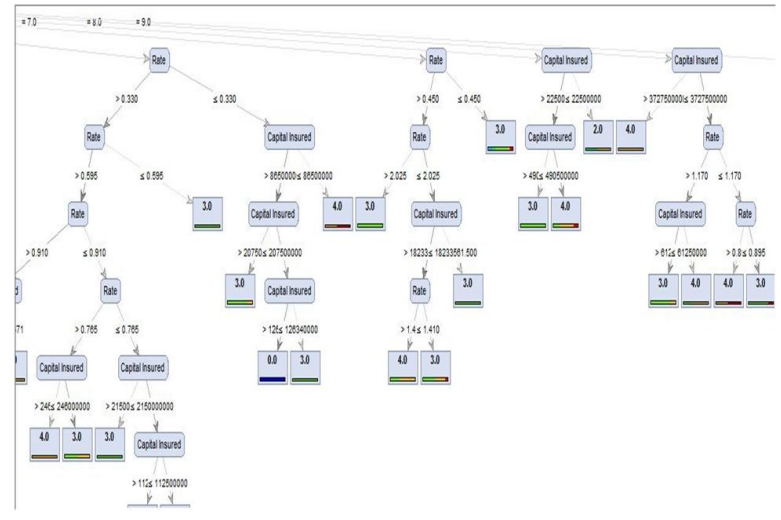

Figure 1: Part of Graphic output of tree model in terms of customers' loyalty

The obtained results show that, for instance, insurance policies belonging to the class of risk 1 , and their rate is less that 1.62 and more than 1.37, and also their capital is more than $160,000,000$ with the share of $1 \%$ are placed in class 0 . That is, these customers do not have any insurance records in Alborz insurance. Insurance policies belonging to the class of risk 8 , and their rate is more than 1.17, and also their capitals are more than $61,250,000$ and less than $372,750,000$ are placed in class 3 with the share of $0.9 \%$. This means that these customers have insurance records for three years, and this indicates the customers' loyalty for three years.According to figure 2 , the rate and amount of proper prediction of data in tree model is about $82.69 \%$.

\begin{tabular}{|c|c|c|c|c|c|c|c|}
\hline \multicolumn{8}{|c|}{ 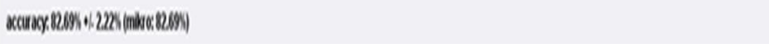 } \\
\hline & bollo & two 10 & toneso & WN130 & wo 10 & coso & claspovion \\
\hline DNOOO & 181 & 17 & 1 & 1 & 1 & 1 & $466 \%$ \\
\hline Wou 10 & 1 & 1 & 1 & 0 & 0 & 1 & $111 \% 3$ \\
\hline $\operatorname{mos} 20$ & 1 & 1 & 0 & 1 & 0 & 1 & $000 x$ \\
\hline NoN 30 & 1 & 1 & 1 & 148 & 18 & 18 & SISSK \\
\hline 010 & 1 & 0 & 0 & $n$ & 21 & 1 & $x 02 \pi$ \\
\hline meso & 1 & 0 & 0 & 1 & 0 & 1 & $000 \%$ \\
\hline casumal & $10000 \%$ & $128 \%$ & DOOK & 1600\% & $2300 \%$ & ous & \\
\hline
\end{tabular}

Figure 2: Precision of tree model

\section{CONCLUSION}

The aim of this research is to investigate and analyze the insured classification in fire insurance of a private insurance. Data that has been extracted through using decision tree method has been analyzed and investigated. According to the obtained results of data analysis related to insurance customers, these customers have insurance records for one year in fire insurance. Decision tree obtained from data mining shows that insurance policies belonging to the class with less risk don't indicate that they have more records. Insurance policies belonging to class with the risk of less than three years show one year record. In addition, sixty nine percent of the persons have bought insurance policy for the first time, while insurance policies belonging to class with risk of more than three have insurance records for three years. Almost $67 \%$ of the insured have insurance records for more than three years.

Based on the collected information, it has been demonstrated that those customers who have insurance policy with more risk show more loyalty. These persons extend their own insurance policy every year because they feel danger in terms of their own properties.

\subsection{Suggestions for Future}

According to the obtained experimental results, the customers having insurance policy with less risk show less inclination toward extending insurance policy in the company. Probably, one of the reasons is the less danger of these insurance policies. Since insurance policies having less risk are less damaged thanothers, and are more profitable,retention of the customers has great importance. The concentration of marketing activities is on the sales of insurance policies with less risk; therefore, damages will decrease, and profitability will increase for insurance companies. 
International Journal of Computer Applications Technology and Research

Volume 2- Issue 6, 637 - 640, 2013, ISSN: 2319-8656

\section{REFERENCES}

[1] Chalmeta, R. " Methodology for customer relationship management", The Journal of System and Software, 2005, 15:192-201.

[2] Gayle, S. 2000. Data Mining in the Insurance Industry. SAS Institute Inc.

[3]Gharehnezhad, S. (2010) The Necessity of Insurance Customer Retention Through Using Data Mining Techniques and Tools. Insurance Research, New World of Insurance, 150-151:2.
[4] Hosseinzadeh, L. 2007. Classification of Target Customers in Insurance Industry Through Using Data Mining. M.A. Thesis. TarbiatModarres University.

[5] Catler, F. 2003. Marketing management of Analysis, Planning, Executing and Controlling. Translated by Forouzandeh, B. Tehran, Taripat

[6] Ling, R., Yen, D. C. "Customer relationship management: an analysis framework and strategies", Journal of Computer Information Systems, 20001, 41, 82-97. 